\title{
Experimentar, devir, contagiar: o que pode um corpo?
}

Kátia Maria Kasper *

Resumo: Aliando-nos aos clowns - e também aos xamãs e outros — investigamos as potências do corpo, em ressonância com processos de singularização. O corpo clownesco - com seu poder de afetar e ser afetado, com sua lógica própria, envolvendo modos de sentir, pensar, agir, singulares - é um dos eixos da construção do clown. A iniciação clownesca - tal como a praticada pelo Lume: Núcleo Interdisciplinar de Pesquisas Teatrais da Unicamp - torna-se uma experiência de devir-outro, invenção de outros afectos, envolvendo uma atitude de escuta do mundo com o corpo todo, um estado de alerta e, ao mesmo tempo, de grande entrega e disponibilidade. Trata-se das ressonâncias dos encontros, de algo que ocorre entre o clown e o outro. As dimensōes ética, política, estética e filosófica estão imbricadas nesse aspecto de afirmação da vida, na construção de outros modos de existência.

Palavras-chave: corpo; educação; singularização; experimentação; clown.

Experiencing, becoming, affecting: what can a body do?

Abstract: Allied to clowns - and also to shamans and others - we investigate the power of a body, in resonance with singularization processes. The clown's body - with its power of affecting and being affected, with a logic of its own, involving ways to feel, think, and act singularly - is one of the axles for the construction of a clown. One's initiation as a clown - as it is practiced at Lume: Interdisciplinary Centre for Theatrical Research at Unicamp - becomes an experience of 'becoming someone else', inventing other kinds of affection, involving an attitude of listening to the world with the whole body, in an alert state and, at the same time, of great dedication and availability. It is related to the resonances of encounters, of something that occurs between a clown and another person. The ethical, political, aesthetic and philosophical dimensions are imbricated in this aspect of affirmation of life, and in the construction of other modes of existence.

Key words: body; education; singularization; experimentation; clown.

Quem experimenta? O corpo. Quem inventa? Ele. ${ }^{1}$

(Michel Serres)

Essa afirmação da potência do corpo por Michel Serres ressoa com aquela de Espinosa, em sua Ética, de que não sabemos ainda o que pode um corpo.

\footnotetext{
* Professora do Departamento de Teoria e Prática de Ensino do Setor de Educação da Universidade Federal do Paraná (UFPR), Brasil. katiakasper@uol.com.br

।. Tradução nossa.
}

Pro-Posições, Campinas, v. 20, n. 3 (60), p. 199-213, set./dez. 2009 
Luiz Orlandi, ao organizar um minidesfile de corporeidades — distribuídas em seis linhas de indagação a propósito do corpo, traçadas pelo pensamento ocidental —, situa Espinosa em uma terceira grande linha de indagação. Se na primeira linha o corpo é tomado como estrito objeto da ciência, sendo interrogado em termos de suas funções, na segunda ele se torna instrumento da alma. Já na terceira linha temos "o corpo como questão que se impõe às variaçōes de todo e qualquer modo de pensar.". É com Espinosa, conforme Orlandi, que se tem "a plena consciência filosófica do corpo como questão que se impõe." (2004, p. 4). Essa linha não considera Descartes como ponto de partida moderno para soluçōes a respeito das relações entre alma e corpo. Tais questôes já aparecem entre os estóicos, em Lucrécio e outros. Leibniz, por sua vez,

mostra o quanto um ponto de vista não se define a partir da posição privilegiada de um sujeito, mas é, isto sim, uma complexa interseção entre o que ele percebe clara e distintamente e a porção de mundo que ele só apreende confusa e obscuramente. (Orlandi, 2004, p. 3).

Aquela afirmação de Espinosa produziu um grande susto na prepotência das almas, repercutindo variadamente em Hume, no idealismo alemão, em Schopenhauer, em Bergson ... (Orlandi, 2004).

É com Nietzsche que, no final do século XIX, reabrem-se novas linhas de indagação nessa perspectiva. Em Assim falou Zaratustra, ele diz sua palavra aos "desprezadores do corpo", de modo a barrar o delírio de uma alma em pretender instrumentalizar o corpo.

"Eu sou corpo e alma" - assim fala a criança. E por que não se
deveria falar como as crianças?
Mas o homem já desperto, o sabedor, diz: "Eu sou todo corpo
e nada além disso; e alma é somente uma palavra para alguma
coisa no corpo".
O corpo é uma grande razão, uma multiplicidade com um
único sentido, uma guerra e uma paz, um rebanho e um pastor.
Instrumento de teu corpo é, também, a tua pequena razão,
meu irmão, à qual chamas "espírito", pequeno instrumento e
brinquedo da tua grande razão.
"Eu" - dizes; e ufanas-te desta palavra. Mas ainda maior - no
que não queres acreditar - é o teu corpo e a sua grande razão:
esta não diz eu, mas faz o eu.
Aquilo que teus sentidos experimentam, aquilo que o espírito
conhece, nunca tem seu fim em si mesmo. [...]
Instrumentos e brinquedos, são os sentidos e o espírito; atrás 
deles acha-se, ainda , o ser próprio. O ser próprio procura também com os olhos dos sentidos, escuta também com os ouvidos do espírito. [...]

Atrás de teus pensamentos e sentimentos, meu irmão, acha-se um soberano poderoso, um sábio desconhecido — e chama-se o ser próprio. Mora no teu corpo, é o teu corpo. (Nietzsche, 1977, p. 51).

Nietzsche afirma ainda que os pulos e os vôos do pensamento são um simples rodeio para o ser próprio - entendido este como "andadeiras do eu e o insuflador dos seus conceitos" - chegar aos seus fins. "O ser próprio diz ao eu: 'Agora sente dor!' E, então, o eu sofre e reflete em como poderá não sofrer mais - e para isto, justamente, deve pensar. O ser próprio diz ao eu: 'Agora sente prazer!' E, então, o eu se regozija e reflete em como poderá ainda regozijar-se muitas vezes - e para isto, justamente, deve pensar." (1977, p. 52, grifos do autor).

Como não consegue criar mais para além de si, o ser próprio dos desprezadores do corpo quer morrer, volta-se contra a vida. "Perecer quer o vosso ser próprio, e por isso vos tornastes desprezadores do corpo!” (Nietzsche, 1977, p. 52).

Tendo o corpo se tornado questão que se impõe ao pensamento, nossa contemporaneidade, conforme Orlandi, "envolve-se com pelo menos mais três linhas filosóficas de indagação, firmando-se em cada uma delas uma maneira distinta de corresponder a esse advento": o "corpo próprio", da experiência fenomenológica; Michel Foucault e "o corpo procurando saídas em meio a saberes e poderes"; Gilles Deleuze e Félix Guattari e "os corpos sem órgãos no intensivo dos encontros".

Corpos sem órgãos que aparecem como coesões ou imantações momentâneas de linhas de fuga, operando como variáveis consistentes dessas linhas. Situados, conforme Orlandi, entre "a funcionalidade do corpo orgânico e a intempestiva conectividade desejosa, mas sem confundir-se com a intencionalidade do corpo próprio ou com o corpo investido de saberes e poderes." (2004, p. 10).

Como consistência, o Corpo sem Órgãos

é o intensivo que vibra nas imantações passageiras de umas linhas pelas outras por ocasião de encontros; passageiras imantações, repito, mas o suficiente para que se possa determinar qual é a singularidade do $\mathrm{CsO}^{2}$ que está me pegando aqui e agora. Por isso é que eu posso até certo ponto interferir na criação de corpos sem órgãos para mim. (Orlandi, 2004, p. 11)

2. Corpo sem Órgãos. 
Dizendo respeito às práticas que cuidam da imantação, da magnetização das fugas, o Corpo sem Órgãos implica cuidados éticos e estéticos.

Estamos, neste artigo, voltados para esta última linha, cuja noção de Corpo sem Órgãos está em ressonância com a leitura que esses autores fazem de Espinosa (Deleuze; Guattari, 1980; Silva, 2007).

Investigando conexões entre as potências do corpo e as políticas de subjetivação, pesquisamos diversos processos de construção do clown, em artes cênicas (Kasper, 2004). Experiências singulares e singularizantes de formação, vividas por atores e atrizes que atuam como clown, marcadas pela invenção de modos de vida (Deleuze, 1965). Focalizaremos aqui o processo de iniciação ao clown desenvolvido pelo Núcleo Interdisciplinar de pesquisas teatrais da Universidade Estadual de Campinas - Lume.

Nossas investigações são atravessadas pela problematização do que escapa ao controle em uma sociedade (Deleuze; Guattari, 1980). Para além de uma análise em termos de biopoder e biopolitica (Foucault, 1989; 1995; 1999), seguindo uma certa "inversão" feita por Maurizio Lazzarato no conceito de biopolítica — passando de poder sobre a vida para potência da vida —, estamos aqui voltados para a biopotência (Lazzarato, 2000; Pelbart, 2003).

Mais do que os poderes sobre os corpos, a potência do corpo. Se, para Foucault, em sua teoria do poder, uma sociedade não se contradiz, mas estrategiza-se, para Deleuze (1996) um campo social não se contradiz, mas ele foge, e isto é primeiro. Uma sociedade define-se por seus fluxos de desterritorialização, por suas linhas de fuga. Cabe a cada um de nós inventar suas linhas de fuga e, para isso, precisamos traçá-las "efetivamente, na vida". A arte clownesca - que, nas últimas décadas ganhou novos contornos, locais e ressurgiu com grande vitalidade nos mais diversos territórios —, pode ser uma poderosa aliada em tal traçado.

\section{Iniciação clownesca}

Ao pensarmos em clowns, em palhaços, referimo-nos não apenas a uma tradição ligada ao circo, ao teatro, mas também às ruas, às feiras, aos bobos da corte, aos bufóes, aos clowns sagrados de povos indígenas. Pensamos também no cinema, em Charles Chaplin, Buster Keaton, nos clowns de Federico Fellini, como aqueles de I clowns, como Gelsomina em La Strada.

A arte do palhaço tem sido constantemente reinventada, em vários campos de atuação. Aprender a ser clown envolve processos diversos: os artistas circenses podem aprender no próprio circo; outros precisam encontrar "escolas" e mestres; alguns aprendem atuando nas ruas, no contato direto com as pessoas. Podem-se combinar os vários modos. Percebemos, a partir das últimas décadas 
do século XX, um forte movimento envolvendo artistas de vários países em torno da figura do clown, principalmente ligado a atores de teatro, mas não só.

Ainda na década de 1960, na França, a École Internationale de Théâtre dirigida por Jacques Lecoq, iniciou uma pesquisa a respeito do clown, criando um procedimento metodológico para construir um "clown pessoal". Essa terminologia foi criada por Lecoq a partir de suas experimentações, quando, segundo ele, percebeu que "o clown não existe fora do ator que o representa".

A busca do seu próprio clowné, em primeiro lugar, a busca de sua própria insignificância. Diferentemente da Commedia dell'Arte, o ator não entra em um personagem pré-estabelecido, mas descobre em si as partes clownescas que o habitam. Quanto menos se defende, menos tenta representar um personagem, mais o clown aparece forte. (Lecoq, 1997, p. 154).

Já no final dos anos 1980, a pesquisa com o clown encontrou-se, no Núcleo Interdisciplinar de Pesquisas Teatrais da Universidade Estadual de Campinas — Lume -, com suas próprias investigações em antropologia teatral, enriquecendo-se no contato com sua técnica chamada de dança pessoal ou dança das vibraçôes. Este núcleo de pesquisa — criado em 1985, por Luis Otávio Burnier, visando, principalmente, investigar e construir técnicas não-interpretativas para o ator - produziu metodologias próprias para o trabalho com o palhaço, seguindo a linha do "clown pessoal" para recriá-la, ampliando suas dimensões.

Em 1995, participei, como "observadora", de um processo de iniciação ao clown, coordenado por Ricardo Puccetti e Carlos Simioni, do Lume. Iniciação que foi um dos pontos de partida de minha pesquisa no tema.

O trabalho de clown é bastante difícil e elaborado, podendo ser construído de várias maneiras. Na perspectiva do trabalho do Lume - assim como para Lecoq e outros -, o clown não é um personagem, no sentido de um papel a ser interpretado por um ator. Ele está relacionado à exploração, à ampliação de aspectos ingênuos, ridículos, paradoxais, etc., ligados ao mundo de cada ator. Podemos ir além, dizendo que se trata também da produção de si, de reinventarse. De processos de subjetivação nos quais se aprende, experimentam-se variações de si. E também a abertura de mundos outros. Aprende-se a experimentar possibilidades novas, a fugir dos automatismos, dos padrōes. $\mathrm{O}$ palhaço brinca com isso, tornando visíveis as armadilhas da norma, evidenciando esse jogo. Várias das atuaçôes de palhaças, por exemplo, operam assim, ao questionar, dos mais diversos modos, os padrões de beleza, de comportamento, de relacionamento. Evidenciar os aspectos do corpo do artista que escapam aos padróes vigentes, criando um jogo cênico, explorando seu potencial cômico, faz parte do próprio modo de criação do clown para a escola de Lecoq e para o Lume. 
Conforme veremos adiante, esse corpo, no entanto, não se restringe ao organismo, a uma forma.

O processo de iniciação elaborado pelo Lume, chamado de "Encontro para estudo e iniciação do clown pessoal", consistiu em nove dias de trabalho realizado em local isolado, do qual os integrantes (quinze participantes, mais os dois coordenadores, Carlos Simioni e Ricardo Puccetti) só saíram, para voltar ao cotidiano, no seu término. Produziram-se, com procedimentos específicos, nesse espaço e tempo singulares, maneiras as mais diversas e inusitadas de agir, sentir, pensar. Delas surgiram os elementos iniciais para construir os clowns.

A dinâmica do Encontro compreendeu uma rotina esgotante, com um trabalho corporal extremamente intenso. Desde o primeiro dia, iniciou-se um exercício de desorganização do corpo e dos seus gestos cotidianos, com jogos que buscavam uma mudança do centro gravitacional do corpo de cada um. Dentre eles, destaco aquele no qual os participantes deveriam andar com uma parte do corpo dando o impulso: andar com o pé dando o impulso; depois, quem comandava o andar era o nariz; depois, o ombro, o quadril, o peito, o joelho, o estômago, a mão esquerda... Para que isso acontecesse, foi necessário um grau de intensidade e uma rapidez, além de uma desorganização do andar cotidiano, difíceis de alcançar. Não se trata de representar, mas de fazer; e aparece, na ação, se está ou não acontecendo. A esse jogo foram se juntando outros, oferecendo mais elementos de desorganização.

Tratava-se de um trabalho muito intenso de produção de deslocamentos. Deslocamentos quanto à postura corporal, deslocamentos em relação às atitudes costumeiras, à percepção, às formas habituais de ação e reação, aos modos de sentir, de agir, etc. Uma aprendizagem também no sentido de abrir outras conexões possíveis entre cada participante e tudo o que estava em volta.

Podemos pensar que encontramos aí experimentações que fazem do corpo uma potência que não se reduz ao organismo - um conjunto de funções - e do pensamento uma potência que não se reduz à consciência.

Ao mesmo tempo que criavam situações inusitadas, nonsense, constrangimentos, para provocar ações não-cotidianas dos atores e construir os clowns, os coordenadores mapeavam e exploravam os novos gestos, os novos modos sutis de percepção que começavam a surgir a partir desses deslocamentos. Os atores precisavam aprender a repetir essas ações, a codificá-las. Codificação necessária apenas como uma linha inicial para construir o clown. Não é definitiva, não pode se fixar, a não ser momentaneamente. Sempre se partirá para uma nova linha de fuga, senão o trabalho de ator morre, torna-se "uma caricatura de si mesmo", nas palavras do atual responsável pelo trabalho com clown, Ricardo Puccetti ${ }^{3}$.

3. Entrevista concedida à autora, em 10 de abril de 1999. 
O Lume trabalha com técnicas não-interpretativas, ou seja, o ator não interpreta um personagem que, nas técnicas "convencionais", costuma ser construído a partir de relações psicológicas, memória emotiva, etc. A dança das vibraçôes - já mencionada anteriormente — produz intensidades, dinamiza energia física, desorganiza o corpo como um organismo (que, por exemplo, reproduz ações cotidianas), busca outras possibilidades. Sem interpretar nem imitar, sem querer entender, experimentando.

Se não é a interpretação de um personagem, de que se trata? São as possibilidades de um ator, possibilidades desconhecidas ou ainda não criadas por ele, produzidas no trabalho com as variações de energia, de ações, construídas experimentalmente. E, com o clown, inúmeras possibilidades de relações com outrem, clowns ou não, experimentaçóes com objetos, adereços, produzindo variaçốes em torno de modos de construção de si.

Esta era uma regra do jogo no Encontro: a recusa de qualquer tentativa de interpretar e explicar o que estava acontecendo. Às vezes me parecia o capítulo do chá, em Alice no país das Maravilhas, de Lewis Carroll. Mas essa regra ia ficando clara durante o jogo. Renunciar à interpretação foi, para muitos, um desafio quase intransponível no Encontro. Mas uma exigência constante e necessária para a construção do clown. Enquanto queriam entender, não conseguiam avançar no trabalho.

\section{Gestos em fuga, corpos clownescos no intensivo dos encontros}

Produziam-se, nesse espaço e tempo singulares, maneiras as mais diversas e inusitadas de agir, sentir, pensar, ao mesmo tempo que os participantes eram levados, por um jogo de constrangimentos crescentes, a sair de seus automatismos físicos, deixando escapar os gestos em fuga. Com eles constrói-se o corpo clownesco. Gestos em fuga seriam justamente esses que escapam aos hábitos, ao controle, aos automatismos. Gestos que não são forma e movimento, mas afecçóes provocadas. Todo o trabalho extremamente exaustivo e incansável é feito nesse sentido de produzir essa disponibilidade para o que acontece naquele momento, ampliar a capacidade de deixar-se afetar.

O clown tem lógicas próprias, maneiras próprias de agir, sentir, pensar, modos de existência ligados ao ator que o cria. No processo de iniciação do Lume, inicia-se o trabalho técnico de construção dessas lógicas. Para o Lume, tudo começa pelo corpo, se o entendermos como algo que ultrapassa o corpo biológico. Corpo extrapolando a sua organização como organismo, corpo criado nas experimentações, na intensidade dos encontros. Para pensarmos as experimentações que ocorreram no processo de iniciação, produzimos um campo conceitual, que não separa o racional e o irracional, o natural e o artificial e 
mesmo o natural e o sobrenatural. E que dá primazia ao desejo. Tal questão já está colocada por Antonin Artaud - em quem Guattari e Deleuze se inspiraram para formular o conceito de Corpo sem Órgãos ${ }^{4}$ - quando grita a não separação entre teatro e vida, em seu teatro da crueldade. Sua tentativa de criar um outro teatro não está separada do esforço de criação de um novo modo de pensamento.

O palhaço é amoral, inocente. Está ligado ao anárquico, ao pequeno, ao minoritário, ao que escapa e foge em uma sociedade. Aqueles aspectos seus que cada um aprendeu a esconder, aprenderá agora a mostrar. Irá explorar e criar novas maneiras de fazer as coisas, explorar seu corpo no contato com outros corpos, com o mundo, indo - no nosso ponto de vista - muito além de sua história pessoal. Nessas exploraçôes, que são experimentaçôes vitais, criam-se formas singulares de subjetivação, de abertura para a alteridade, que permitem fugir da identidade, tornar-se outro, aprendendo a rir de si mesmo. "O riso é uma coisa muito poderosa, provoca muitas coisas. Com o riso parece que respiram alguns lugares que estavam duros" - afirma Ricardo Puccetti. ${ }^{5}$

Para fazer um clown é preciso fazer um corpo. Não se trata de um corpo dado, mas um corpo produzido nas diversas experimentaçóes que constituem o processo de construção de um clown. Produzido trabalhando justamente as vulnerabilidades daquele ator e procurando ativar, potencializar a multiplicidade de seres que o habitam, experimentando ao mesmo tempo os mais variados processos.

Corpo capaz de afetar-se também pelas forças da sua época e do momento preciso em que atua. A iniciação clownesca torna-se uma experiência de deviroutro, aprendendo a afetar e ser afetado, envolvendo uma atitude de escuta do mundo com o corpo todo, um estado de alerta e ao mesmo tempo de grande entrega e disponibilidade. Nesse sentido, ele extrapola o termo pessoal, pois trata-se das ressonâncias dos encontros. Trata-se de algo que ocorre entre o clown e o outro - seja uma laranja, uma pessoa, um vento, uma borboleta que passa.

A dança das vibraçôes é construída, conforme afirmou Burnier, fundador do Lume, "com o léxico do ator, com as palavras de uma língua corpóreo-vocal que ele mesmo edificou, desenvolveu e aprimorou." (Burnier, 2001, p. 152). Dança que foge aos passos preestabelecidos, a algo para ser mostrado, mas, como

4. A aproximação feita por Deleuze e Guattari entre o termo Corpo sem Órgãos — forjado por Antonin Artaud - e a concepção espinosista do corpo (e sua articulação com a mente) encontrase desenvolvida em Corpo e pensamento: alianças conceituais entre Deleuze e Espinosa (Silva, 2007). Ainda a respeito do conceito de Corpo sem Órgãos, ver: Deleuze; Guattari ( 1 980); Lins (1999).

5. Entrevista concedida à autora em 21 de junho de 2002. 
disse o dançarino de butoh Hijikata, sua dança absurda segue uma lógica "que tem mais a ver com o sangue, com 'a dimensão prática da vida do homem, seu instinto animal, sua natureza primitiva'” (Hijikata, 1988, p. 186, apud Burnier, 2001, p. 144). Dança que

trabalha com essas ações recorrentes segundo as diversas qualidades de energia, usando de diferentes dinâmicas muitas vezes lentas e vagarosas, em que o tópico é ouvir-se, buscar e explorar formas de articular, por meio do corpo, as energias potenciais que estão sendo dinamizadas, de ser fazendo e no fazer, de dar forma à vida (Hijikata, 1988, p. 186, apud Burnier, 2001, p. 144).

Ao mesmo tempo que esses fluxos são investigados, explorados, o clown traz a necessidade de conectar-se com o público, com o outro, tornando essa dança uma criação que envolve a ressonância entre os corpos e não apenas um ator voltado para si mesmo.

O corpo é o grande diferenciador na arte clownesca. Corpo que ultrapassa uma forma desenhada pelo figurino e pela maquiagem, compreendendo um "feixe de impulsos". Corpo preparado para "pensar em movimento", criado na experimentação, exposto, disponível para o jogo.

Corpos gerados na produção de outras lógicas, outros modos de sentir, agir, pensar.

Tais processos são atravessados por uma política específica de relação com a alteridade, que pressupóe, necessariamente, uma abertura para o outro. A abertura para deixar-se capturar pela imprevisibilidade da vida é fundamental na arte do palhaço. Não só deixar-se atravessar pelos imprevistos, mas também produzi-los, operar na imprevisibilidade: arriscar-se. Vemos construir-se um trabalho de preparação para a improvisação, essa difícil e importantíssima técnica. A relação com o tempo é fundamental na arte clownesca e na improvisação. $\mathrm{O}$ ator, para construir o clown, precisa produzir uma inteligência corporal capaz de, ao mesmo tempo, agir de modo extremamente rápido e muito lentamente, conforme a situação. Aprender a abrir-se para escutar o que está fora sem reagir mecanicamente —, a produzir mudanças de estado instantâneas: num instante pode estar amargurado, mas algo acontece e ele salta alegremente, de imediato. $\mathrm{O}$ ator enfrenta o desafio de experimentar essas metamorfoses, aprender esse jogo, fazer-se assim.

\section{Entre xamãs e metamorfoses, aprendendo por contágio}

A iniciação: um processo de produção de corpos. Produção coletiva de corpos singularizados, mas que, ao mesmo tempo, constituem um corpo coletivo, 
partilhado por todos, pois o que cada um faz com seu corpo afeta terrivelmente os outros. Processo de contágio, contaminação. Nesse sentido específico e preciso, os coordenadores fazem o papel do xamã, o que detém uma tecnologia somática singular. Tal concepção de xamã apreendemos principalmente com Eduardo Viveiros de Castro, construída em seus estudos a respeito do estatuto do corpo para os ameríndios. Para estes, a alma é formalmente idêntica através das espécies, sendo a diferença dada pela especificidade dos corpos. Não é o corpo orgânico que é diferente, mas os

afetos, afecções ou capacidades que singularizam cada espécie do
corpo: o que ele come, como se move, como se comunica, onde
vive, se é gregário ou solitário... A morfologia, a forma visível dos
corpos, éum signo poderoso dessas diferenças de afecção, embora
possa ser enganadora, pois uma aparência de humano, por exem-
plo, pode estar ocultando uma afecção-jaguar. O que estou cha-
mando de "corpo", portanto, não é sinônimo de fisiologia distin-
tiva ou de morfologia fixa; é um conjunto de afecçôes ou modos
de ser que constituem um habitus. Entre a subjetividade formal
das almas e a materialidade substancial dos organismos, há um
plano intermediário que éo corpo como feixe de afecçôes e capa-
cidades, e que é a origem das perspectivas. (Viveiros de Castro,
2000, p. 438, grifo e aspas do autor).

Para os ameríndios, a construção do corpo é um trabalho social fundamental. Sendo o corpo o grande singularizador, e não a alma, o trabalho do xamã envolve a produção de tais corpos; e, para tal, detém uma tecnologia somática específica.

O xamã transita entre as coisas deste mundo, entre os objetos, os animais, as plantas e os outros seres e elementos cosmológicos, estabelecendo uma comunicação entre eles. Domina o processo de metamorfose, podendo aliar-se às forças de objetos, de outros seres, pode transformar-se em jaguar, em planta... As metamorfoses, cuja técnica os xamãs dominam, são ao mesmo tempo um modo de escapar ao poder (Canetti, 1983) e um modo de operar também do clown. O processo observado de construção do clown também envolve um conhecimento a respeito de como produzir metamorfoses, como se aliar a elementos heterogêneos em coexistência virtual. Dentre as técnicas comuns encontramos a produção de uma atitude de abertura, de um estado de alerta e de conectividade.

A metamorfose ameríndia está ligada, conforme Viveiros de Castro, à doutrina das roupas animais. Os xamãs, ao referirem-se ao processo de metamorfose em animal, dizem que vestiram a roupa dele. Transforma-se em onça vestindo a roupa da onça. Vestir a roupa seria produzir o agenciamento, produzir o 
equipamento para apreender algo da potência do animal. Nas narrativas dos ameríndios, elas remetem mais à função do que à forma.

Vestir uma roupa-máscara é menos ocultar uma essência huma-
na sob uma aparência animal que ativar os poderes de um corpo
outro. As roupas animais que os xamãs utilizam para se deslocar
pelo cosmos não são fantasias, mas instrumentos: elas se aparen-
tam aos equipamentos de mergulho ou aos trajes espaciais, não
às máscaras de Carnaval. O que se pretende ao vestir um esca-
fandro é poder funcionar como um peixe, respirando sob a
água, e não se esconder sob uma forma estranha. Do mesmo
modo, as "roupas" que, nos animais recobrem uma "essência"
interna de tipo humano não são meros disfarces, mas seu equi-
pamento distintivo, dotado das afecçôes e capacidades que de-
finem cada animal. (Viveiros de Castro, 2000, p. 443-444,
aspas do autor).

Através de algumas técnicas, vimos no processo de iniciação ao clown estudado, a criação de outras conexões possíveis entre cada participante e tudo o que estava em volta. Tratava-se de fenômenos sutis, mas podemos entendê-los como processos de diferenciação que afetam o que está em torno, produção de outros modos de sentir.

A metamorfose, a necessidade de abertura para o inesperado e a técnica de improvisação estão unidos no modo de operar do clown, na perspectiva estudada. Vejamos com mais detalhes.

\section{Improvisação e conexão com o fora — o que pode um clown?}

Ricardo Puccetti (Kasper, 2004, p. 334) afirma que antes de cada apresentação tenta colocar-se numa situação de não saber exatamente o que fará. Por exemplo, sabe que vai apresentar La Scarpetta - seu espetáculo solo de clown —, mas a maneira como o fará naquele dia, para aquele público, ele não sabe e terá que descobrir. Postura que coloca o artista numa corda bamba, meio inseguro, mas, ao mesmo tempo, "é uma insegurança que não é descontrolada porque você tem técnica, tem experiência. Isso aguça a capacidade de ouvir o que acontece no momento, faz com que o público se sinta parte da coisa" (Kasper, 2004, 334). O processo de preparação para fazer o clown, diz Puccetti, "é para o artista ir até o fim do seu impulso. Propôs uma coisa, tem que levá-la até o fim. Isso envolve técnica, controle do corpo, capacidade de antever os problemas." (Kasper, 2004, p. 333). Lembramos aqui do corpo preparado para pensar em movimento, mencionado anteriormente. De uma certa maneira, diz Ricardo, você se sente seguro no risco. "É bem paradoxal, porque você 
está inseguro, e é real. Mas, ao mesmo tempo, você conta com seus recursos nas dificuldades. Como um gato que, jogado para cima, sempre cai em pé" (Kasper, 2004, p. 333). A improvisação requer toda essa técnica.

Segundo Puccetti, no processo de iniciação experimenta-se o estado de clown, que é

um estado primeiro, da vivência de estar de frente para o público, deixando-se ver, expondo-se. Isso é uma vivência. A vivência de não fazer, de deixar que as coisas que se fará surjam deste não fazer, serem consequiência desse "vazio". Tal vivência não é suficiente para você ser clown. Depois é necessário aprender muitas coisas, treinar o corpo, a mente, os olhos, para ver as coisas. (Kasper, 2004, p. 334).

Puccetti afirma que, para ele,

manter esse estado da revelação é você ter essa capacidade de ter os impulsos e fazer. Durante a iniciação você é levado, naquele momento, a experienciar esse estado, mas depois você tem que fazer por si mesmo. É como se você reaprendesse novamente, a cada vez, a entrar naquela situação, naquele estado. (Kasper, 2004, p. 334).

Puccetti diz que se trabalha para ser um conjunto de impulsos, para que consiga pensar e agir simultaneamente, "ter a idéia e já estar fazendo. Sem saber o que veio antes: se você fez e daí teve a idéia, ou se teve a idéia e fez". Para ele, o clown "não é fixo, ele se transforma, na medida em que você se transforma, e os seus impulsos se transformam." Pode-se trabalhar com isso de modo diverso, "mudando tudo, como alguns fazem, ou mantendo uma base, mas que é uma base que está sempre fazendo coisas diferentes." (Kasper, 2004, p. 334). O treinamento é para abrir e não para fechar, afirma.

O trabalho com o risco "envolve a capacidade de usar as coisas que acontecem a teu favor, que é uma técnica e também é um estilo". Não são todos os palhaços que trabalham assim, diz Puccetti (Kasper, 2004, p. 55). Afirma que o seu risco cada vez mais se acentua em sentir-se "um conglomerado de impulsos e, mesmo que eu tenha a minha estrutura de espetáculo, de número, isso não é nada; posso largar tudo isso na hora e fazer outra coisa, se for levado para isso. Meu risco é esse. Um deles, talvez." (Kasper, 2004, p. 55). Ele conta a respeito de um jogo no qual comia banana e, quando a banana acabou, comeu a casca. O jogo era comer.

Se você propõe algo, o público quer ver. Se você apostou, o público quer ver até onde você vai. Se você não vai até o limite, pode 
perder o público. Porque o público sente: Ah! Você não éverdadeiro, vocêfaz que vai fazer, mas não faz! Isso dentro de um jogo, não é nada realista. É dentro do jogo. Você propôs, a tua lógica é fazer aquilo, então você tem que seguir, tem que ir até onde isso vai dar. Porque o público quer e porque, se você corta, fica sem saber para onde ir, porque perde o fluxo. Quanto mais você extrapola algo que você propôs — ou uma ação, ou uma relação, ou um jogo com alguém - isso se transforma em outra coisa quase que sem você saber. (Kasper, 2004, p. 335, grifo nosso).

Enuncia-se novamente o modo de operar do clown através da metamorfose, e também como o clown é jogado pelo jogo, sendo o próprio jogo que transforma um jogo em outro, num fluxo sem fim.

Levar às últimas conseqüências, não buscar uma causa, não buscar um princípio, não retroceder, como na ironia. Mas tomar tudo literalmente, esperando pelas conseqüências, pelos efeitos. Assim diz Deleuze do humor (Deleuze, 1983, p. 88-98). Para ele, o humor é uma forma de pensar e uma forma de relacionar-se com a lei. Assim como a lei torna o tirano possível, o humor revira a lei "pelo excesso de zelo", pelo "aprofundamento das conseqüências", tomando-a ao pé da letra. Diante de uma regra proposta, ou de um jogo proposto, revirase a regra levando-a às últimas conseqüências. Não se questiona o que é proposto barrando, mas trai-se o jogo jogando, aplicando suas regras, levando-as ao extremo, ao absurdo.

Configura-se esse novo corpo e sua potência: conglomerado de impulsos, que atuam em um fluxo de metamorfose. Nas palavras de Puccetti, o clown "não tem uma forma fixa e definida, ele é um conjunto de impulsos vivos e pulsantes, prontos a se transformarem em ação no espaço e no tempo.” (Kasper, 2004, p. 55)

Improvisar, transformar-se, arriscar-se, reinventar-se. Salientamos a própria potência política dos processos de construção de um clown e dos seus modos de atuação artística, a vitalidade de suas invençôes. Os modos de operar dos palhaços e os processos de construção do palhaço pelo ator que o faz podem ser pensados como invençôes de si, em ressonância com os outros, com o mundo. Invenções que operam com a difícil aprendizagem de rir de si mesmo.

Vemos emergir tal abertura para a alteridade como um processo de subjetivação que passa pelo jogo, pelo riso trágico, por um rebaixamento da hegemonia do ego e suas pretensões de controle, por uma liberdade de experimentação, em função das urgências a serem enfrentadas. E também uma aprendizagem em torno de tornar-se outro. E um tornar-se outro que se faz na vizinhança de outrem, pois não existe palhaço sem a relação com o público. Potência de afetar e ser afetado. 
Esses modos de agir, de sentir, pensar - envolvendo uma atitude de escuta do mundo com o corpo todo, uma abertura, um estado de alerta e de conectividade - abordam uma experiência da ordem do intensivo. Um tipo de vibração que extrapola os limites do corpo orgânico. Envolve o lugar, tudo o que está em volta. São processos de diferenciação pulsando.

\section{Referências bibliográficas}

BURNIER, Luís Otávio. A arte de ator: da técnica à representação. Campinas: Ed. da Unicamp, 2001.

CANETTI, Elias. Massa e poder. Tradução de Rodolfo Krestan. São Paulo: Melhoramentos, 1983.

DELEUZE, Gilles. Apresentação de Sacher-Masoch. Tradução de Jorge de Bastos. Rio de Janeiro: Livraria Taurus Editora, 1983.

DELEUZE, Gilles. Desejo e prazer. Cadernos de Subjetividade. São Paulo: PUC, p. 13-25, jun. 1996.

DELEUZE, Gilles; GUATTARI, Félix. Mille plateaux. Paris: Minuit, 1980.

FOUCAULT, Michel. Vigiar epunir. Tradução de Raquel Ramalhete. 7 ed. Petrópolis: Vozes, 1989.

FOUCAULT, Michel. Dits etécrits IV. Paris: Gallimard, 1995.

FOUCAULT, Michel. Em defesa da sociedade. Tradução de Maria Ermantina Galvão. São Paulo: Martins Fontes, 1999.

GUATTARI, Félix; ROLNIK, Suely. Micropolítica: cartografias do desejo. 4. ed. Petrópolis: Vozes, 1996.

KASPER, Kátia M. Experimentaçoes clownescas: os palhaços e a criação de possibilidades de vida. 2004. 412 p. Tese (Doutorado em Educação) — Faculdade de Educação, Universidade Estadual de Campinas, Campinas.

LAZZARATO, Maurizio. Du biopouvoir à la biopolitique. Multitudes. 1 mars 2000. Disponível em: <http://multitudes.samizdat.net/article.php3?id_article=298> Acesso em: 25 mar. 2005. LECOQ, Jacques. Le corpspoétique. Arles: Actes Sud-Papiers, 1997.

LINS, Daniel. Antonin Artaud: o artesão do corpo sem órgãos. Rio de Janeiro: Relume Dumará, 1999.

NIETZSCHE, Fridrich W. Assim falou Zaratustra. Tradução de Mário da Silva. Rio de Janeiro: Civilização Brasileira, 1977.

ORLANDI, Luiz B. L. Corporeidades em minidesfile. Revista Eletrônica Alegrar, n. 1, ago. 2004. Disponível em: <http://www.alegrar.com.br/01/corpo/index.html>. Acesso em: 03 ago. 2008. 
PELBART, Peter P. Vida capital. São Paulo: Iluminuras, 2003.

SERRES, Michel. Variations sur le corps. Paris: Le Pommier, 1999.

SILVA, Cíntia Vieira da. Corpo e pensamento: alianças conceituais entre Deleuze e Espinosa. 2007. 278 p. Tese (Doutorado em Filosofia) — Instituto de Filosofia e Ciências Humanas, Universidade Estadual de Campinas, Campinas.

SPINOZA, Benedictus de. Ética. Tradução de Tomaz Tadeu. Belo Horizonte: Autêntica, 2007.

VIVEIROS DE CASTRO, Eduardo. Os pronomes cosmológicos e o perspectivismo ameríndio. In: ALLIEZ, Éric (Org.) Gilles Deleuze: uma vida filosófica. São Paulo: Ed. 34, 2000. p. 421450 .

VIVEIROS DE CASTRO, Eduardo. A inconstância da alma selvagem — e outros ensaios de antropologia. São Paulo: Cosac \& Naify, 2002.

Recebido em 31 de outubro de 2008 e aprovado em 29 de maio de 2009. 